\title{
CARNAVAL DAS ESCOLAS DE SAMBA DA CIDADE DE SÃO PAULO: AS IMPOSIÇÕES DO MERCADO E AS REAÇÕES DO LUGAR*
}

\author{
Vanir de Lima Belo**
}

Resumo: Ao longo de seu desenvolvimento, o carnaval das escolas de samba na cidade de São Paulo passou por diversas transformações acompanhando o crescimento da cidade e adaptando-se aos novos conteúdos urbanos e a imposições políticas e técnicas. Todavia, ainda guarda um caráter genuíno atrelado à festa, característica de sua gênese. Diante disso, o objetivo é compreender a dinâmica territorial das escolas de samba em São Paulo através da análise do processo de produção do carnaval que inclui a ação de diversos agentes na cidade, considerando a tendência à apropriação dessa manifestação popular pela indústria cultural. E analisar a forma como os membros das escolas de samba produzem cultura e fazem política, utilizando-se dos novos conteúdos técnicos que a cidade oferece, para se organizar e buscar formas de suprir suas necessidades.

Palavras-chave: carnaval, cidade, cultura, escolas de samba, São Paulo.

\section{CARNIVAL MADE NY THE SCHOOLS OF SAMBA IN THE CITY OF SÃO PAULO: THE MARKET IMPOSITIONS AND THE PLACE REACTIONS}

Abstract: Throughout its development, the carnival made by the Schools of Samba in the city of São Paulo several changes have occurred, following the city growth and adapting itself to the new urban contents and political and technical impositions. It still keeps a genuine feature related to the party, typical of its genesis. Thus, the objective is to comprehend the territorial dynamics of Schools of Samba in São Paulo through the analysis of the process of carnival production that includes the action of several agents in the city, considering the trend of appropriation of this manifestation by the culture industry. And to analyze the way the members of Schools of Samba produce culture and political actions, making use of new technical contents offered by the city, to organize themselves and search for new ways of fulfilling their needs.

Keywords: Carnival, city, culture, school of samba, São Paulo.

\section{Introdução}

O entendimento da cidade de São

Paulo passa pela compreensão dos mais diversos aspectos que a caracterizam, como, por exemplo, a existência de manifestações culturais que, na atualidade, apresentam um importante conteúdo social, político e econômico, contribuindo para seu dinamismo, pois ao se realizarem geram ações e relações entre diversos agentes e objetos.
Dentre essas manifestações está o carnaval que, ao longo de seu desenvolvimento, passou por diversas transformações acompanhando o crescimento da cidade e adaptando-se aos novos conteúdos urbanos e às imposições políticas e técnicas, sendo as escolas de samba uma adaptação dos cordões carnavalescos criados no início do século $X X$.

\footnotetext{
* Artigo elaborado a partir da dissertação de mestrado 0 enredo do Carnaval nos enredos da cidade: dinâmica territorial das escolas de samba em São Paulo, desenvolvida sob a orientação da Prof $^{a}$ Dr $^{\text {a }}$ Mónica Arroyo, no Programa de Pós-graduação em Geografia Humana do Departamento de Geografia da Faculdade de Filosofia, Letras e Ciências Humanas da Universidade de São Paulo, defendida em 2008.

** Mestre em Geografia. Professora e coordenadora do curso de licenciatura em Geografia na Universidade Bandeirante de São Paulo. E-mail: vanirbelo@usp.br.
} 
Símbolo da cultura brasileira, o carnaval das escolas de samba tornou-se um espetáculo que, na sua produção, movimenta milhões de reais a cada ano e cria um número significativo de postos de trabalho diretos e indiretos, além de fomentar uma série de negócios afins. Todavia, essa manifestação ainda guarda um caráter genuíno atrelado à festa, característica de sua gênese e, além disso, as agremiações carnavalescas promovem diversas ações sociais nos bairros que as abrigam.

Diante disso, faz-se necessário compreender a dinâmica territorial das escolas de samba em São Paulo através da análise do processo de produção do carnaval que inclui a ação de diversos agentes na cidade, considerando a tendência à apropriação dessa manifestação popular pela indústria cultural. E analisar a forma como os membros das escolas de samba produzem cultura e fazem política, utilizando-se dos novos conteúdos técnicos que a cidade oferece, para se organizar e buscar formas de suprir suas necessidades.

\section{Uma periodização necessária}

A análise da dinâmica territorial das escolas de samba em São Paulo exige, a compreensão do processo de desenvolvimento dessa manifestação na cidade, fazendo-se necessária a elaboração de uma periodização que a considere a partir de seu surgimento, o que contribui sobremaneira para a interpretação dos eventos. Ao considerar o carnaval de São Paulo a partir do surgimento do primeiro cordão carnavalesco popular paulistano, em 1914, até os dias atuais, é possível definir um quadro composto por três períodos. São eles:

- Carnaval dos cordões - do surgimento dos cordões carnavalescos em 1914 à oficialização do carnaval em 1967 - que abrange o surgimento, o desenvolvimento e a multiplicação dessa manifestação em São Paulo, a qual se adaptou ao crescimento da cidade numa constante busca pelo reconhecimento por parte da sociedade e do poder público. Nesse processo, os agentes privados, baseados em interesses econômicos, atuaram no sentido de impulsionar esse desenvolvimento;

- Carnaval das escolas de samba oficialização e consolidação - do carnaval oficializado em 1968 à inauguração do sambódromo em 1991 - que abrange as transformações decorrentes da oficialização do carnaval das escolas de samba, em 1967, a qual, por um lado, descaracterizou a manifestação popular através da imposição de normas geradas fora de seu contexto original e, por outro, levou à sua consolidação na cidade que, ao crescer e se desenvolver, impôs novos conteúdos e direcionamentos, levando à construção do Sambódromo paulistano;

- Carnaval das escolas de samba profissionalização e ação social - do início dos desfiles no sambódromo aos dias atuais - que engloba o carnaval paulistano a partir de sua regulamentação, em 1990, e do início dos desfiles no Sambódromo, em 
1991, até os dias atuais. Esses eventos impulsionaram o desenvolvimento dessa manifestação que desponta como negócio turístico lucrativo, atraindo 0 interesse de diversos agentes, como a Rede Globo de Televisão, cujas ações são determinantes para as inovações. A transferência dos desfiles para 0 Sambódromo estimulou a redistribuição dos barracões das escolas de samba na cidade e uma nova forma de utilização dos fixos pelas agremiações. Outro fator de grande relevância nesse período foi o desenvolvimento de ações, por parte de algumas escolas de samba, no sentido de se utilizar dos novos conteúdos técnicos e políticos, com a finalidade de atender não apenas aos interesses da produção carnavalesca, mas, também, aos de suas comunidades. ${ }^{1}$

As variáveis chave, determinantes para a ruptura dos períodos, são as normas e as políticas públicas realizadas com a finalidade de desenvolver o carnaval paulistano e, como consequência dessas ações, as divisões sociais e territoriais do trabalho (SANTOS, 1999) criadas na produção dos desfiles carnavalescos em relação aos diferentes circuitos da economia urbana (SANTOS, 1979).

A compreensão dos dois primeiros períodos é fundamental para a compreensão do período atual, pois o centro da discussão se dá neste último; foi a partir da regulamentação do carnaval das escolas de

\footnotetext{
${ }^{1}$ Nesse contexto o termo comunidade refere-se ao grupo de pessoas diretamente envolvidas com as agremiações carnavalescas.
}

samba (Lei No 10.831/1990), da inauguração do sambódromo $(1991)^{2}$ e do início das transmissões dos desfiles pela Rede Globo de Televisão (1999) que o carnaval paulistano ganhou novo impulso e se desenvolveu fortemente, tanto no que se refere à produção dos desfiles como ao desenvolvimento de ações socioculturais.

\section{Ampliação da divisão do trabalho na produção dos desfiles carnavalescos}

Os novos conteúdos exigem das escolas maior organização interna e maior investimento, pois os desfiles tornam-se mais luxuosos e, consequentemente, mais caros. Isso aumenta a disputa entre as agremiações que, mais fortemente inseridas no contexto econômico da cidade, passam a adotar novas estratégias de crescimento, desenvolvimento e obtenção de recursos, ganhando uma estrutura cada vez mais empresarial.

A nova organização das agremiações leva à necessidade de redefinir a forma de produzir o desfile, com a utilização de mão de obra especializada nas diferentes etapas

\footnotetext{
${ }^{2}$ A regulamentação do carnaval e a inauguração do Sambódromo fazem parte de uma política da Prefeitura, cujo objetivo, mais do que promover a manifestação cultural, é desenvolver seu potencial turístico. Essas ações não se caracterizam como políticas isoladas, pois ocorreram num momento em que surgiam diversas ações de incentivo à cultura por parte do poder público em suas diferentes esferas - municipal, estadual e federal como a inauguração do Memorial da América Latina (1989) pelo Governo do Estado de São Paulo e a aprovação das leis federais Rouanet (1991) e do Audiovisual (1993). Em âmbito municipal, a construção do Sambódromo fez parte de uma política de reformulação do Parque Anhembi que, juntamente com a volta da Fórmula I ao autódromo de Interlagos, potencializou as áreas de turismo e lazer em São Paulo. Nesse mesmo período foram aprovadas duas leis referentes à regulamentação do turismo na cidade: a Lei $\mathrm{N}^{\circ}$ 29.509/91, que criou o Conselho Municipal de Turismo e a Lei $N^{\circ} 11.198 / 92$, que implantou o Plano de Turismo Municipal e criou o Fundo Municipal de Turismo.
} 
dessa produção, o que resulta na criação de diversos postos de trabalho e se caracteriza como uma das vertentes da chamada "profissionalização do carnaval". No entanto, isso não reflete a totalidade do período atual, pois há uma série de escolas de samba que apresentam características semelhantes àquelas dos períodos anteriores. São as escolas menores, que não têm acesso aos mesmos recursos e conteúdos das maiores e, por isso, ainda dependem, fundamentalmente, do trabalho voluntário e da utilização das casas dos componentes para produzir e armazenar fantasias e adereços, e realizar suas atividades.

Essa profissionalização, característica comum entre as chamadas grandes escolas, que se traduz na reestruturação da produção dos desfiles, cria uma divisão do trabalho própria, que atende às suas necessidades no que se refere especialmente a produtos $\mathrm{e}$ mão de obra. Analisar o desenvolvimento das escolas de samba a partir da divisão do trabalho, social e territorial (Santos, 1999) é esclarecedor, pois se trata de uma instituição que, a partir de uma receita, produz um evento de grandes proporções (o desfile carnavalesco) que pode ser entendido como seu produto final para cuja realização são contratados trabalhadores de diferentes especialidades e envolvidas firmas de diferentes tamanhos - para contratação de serviços ou aquisição de produtos - ambos provenientes de diversos lugares e, no caso das firmas, inclusive do exterior. O desfile de uma escola de samba, por sua vez, faz parte de um evento maior, o carnaval, que amplia a escala de relações de trabalho e prestação de serviços.

No terceiro período de desenvolvimento do carnaval paulistano - marcado pela regulamentação, pela existência do Sambódromo e pela transmissão televisiva - é possível verificar a sobreposição de divisões do trabalho, cada qual criada num determinado momento, mas relacionando-se na atualidade. Interessante observar que as divisões do trabalho não se distribuem entre as escolas de acordo com sua força, pois mesmo nas maiores escolas há essa sobreposição. Tanto nas pequenas como nas grandes agremiações, é possível observar, por um lado, as relações de trabalho voluntário de pessoas da própria comunidade, o uso de mão de obra pouco qualificada, com fornecimento de matérias-primas de pequenas firmas do próprio bairro ou de bairros vizinhos e, por outro, o uso de mão de obra remunerada, qualificada ou altamente qualificada, sendo uma boa parte dela proveniente de outras cidades e mesmo de outros estados, com a utilização de produtos importados e adquiridos em grandes firmas que fornecem para todo o Brasil e para outros países.

Verifica-se, portanto, a existência de diferentes formas de cooperação na produção carnavalesca. Essa situação é um reflexo do que ocorre na cidade de São Paulo, onde há a sobreposição de divisões do trabalho que convivem e se combinam. Como ensina Santos (1999) são temporalidades diversas e combinadas relacionando-se num determinado lugar.

A contratação de profissionais provenientes de diversas cidades do estado de São Paulo e de outros estados brasileiros é um bom exemplo dessa divisão territorial do trabalho no âmbito da produção carnavalesca. É comum a contratação de profissionais do Rio de Janeiro, como carnavalescos, aderecistas, costureiras, 
intérpretes, entre outros. Bem como a contratação de profissionais de Parintins (AM) para a construção dos carros alegóricos, os quais permanecem em São Paulo cerca de sete meses, de agosto a março, e trabalham a partir de uma técnica que chamam de "engenharia artesanal". Esses trabalhadores são especializados na construção de alegorias com movimentos - devido ao know-how desenvolvido na festa do Boi de Parintins, que, por ocorrer em junho, não compete com o carnaval na contratação da mão de obra e são muito requisitados pelas escolas de samba de São Paulo e do Rio de Janeiro.

De acordo com a Liga Independente das Escolas de Samba de São Paulo (Liga) e com a São Paulo Turismo S/A (SP Turis), o carnaval paulistano gera, anualmente, cerca de vinte e cinco mil postos de trabalho diretos, e são diversos os profissionais que atuam na produção dos desfiles com algum tipo de remuneração. Cada escola do Grupo Especial pode gerar entre cem e duzentos postos de trabalho diretos nos meses próximos ao carnaval, número que varia de acordo com o tamanho da escola e com o valor investido. As relações de trabalho também variam bastante e, no geral, são baseadas em contratos informais. Mas algumas escolas mantêm trabalhadores permanentes com registro formal.

Santos (2000), analisando a produção de emprego nas diversas formas de lazer popular, chama a atenção para o fato que não são apenas as formas organizadas e burocratizadas de lazer praticadas pelas classes médias e superiores que geram trabalho. Segundo o autor "há também um lazer popular, rebelde às estatísticas, produzindo de baixo para cima, formas ingênuas de distração coletiva, provindas do exercício banal da existência, criadas na emoção e geradoras de solidariedade e de trabalho" (SANTOS, 2000, p. 34). Dentre as formas de lazer, Santos distingue as formas puras e as formas impuras, ou mistas, nas quais inclui as escolas de samba. Mas, segundo ele, "todos são, entretanto, animados por músicas importadas e adaptadas ou por ritmos criados nos próprios lugares, representativos do povo fazendo cultura e, por isso mesmo, fazendo política" (SANTOS, 2000, p. 34).

Para a produção dos desfiles as escolas contam com a subvenção da Prefeitura e com diversos investimentos privados, como a venda do direito de imagem para a Rede Globo de Televisão; o patrocínio de empresas ou outras entidades para os enredos anuais; os patrocínios dos comerciantes e empresários locais para a manutenção da agremiação; além dos patrocínios públicos e privados para a promoção e manutenção das diversas atividades sociais desenvolvidas nas agremiações.

A profissionalização do carnaval paulistano, a superposição das divisões do trabalho e os diversos negócios gerados a partir daí, caracterizam-se como elementos marcantes do período atual. E embora por um lado contribuam para geração de emprego, renda, além da formação de diferentes profissionais, por outro, como em todos os setores produtivos, criam um mercado de profissionais e empresas que são rotativos. Para alguns essa situação descaracteriza o carnaval como manifestação cultural, pois a produção artesanal, típica dos períodos anteriores, invocava o amor pela agremiação, o que muito pouco, ao menos nas grandes escolas, se verifica na 
atualidade. Todavia, essas inovações na forma de produzir os desfiles não se difundiram de forma homogênea entre as agremiações carnavalescas.

\section{As escolas de samba no lugar}

O vínculo de algumas escolas de samba com o bairro onde se originaram ainda é muito forte. Muitas delas, independentemente de seu tamanho, necessitam, largamente, das relações ali presentes, embora sua comunidade em muitos casos extrapole os limites do bairro e inclusive da cidade. Mas isso não é exclusividade das escolas de samba, pois, como afirma Seabra (2000, p. 17):

[...] na metrópole, as identidades estão sendo libertadas dos enraizamentos territoriais dos quais o bairro foi, na história urbana, o nível mais elementar. Por isso, os pertencimentos tendem a ser eletivos, fundados em autorreconhecimento. As identidades são mobilizadas para outras esferas da vida e de outras escalas portadoras de outros conteúdos.

No caso de algumas escolas de samba, as relações se dão no bairro, mas a identidade e o sentimento de pertencimento são dados pela própria agremiação, reforçados, ou não, por laços de vizinhança. O que se aproxima daquilo que Magnani (2002) chama de "pedaço", ou seja, o segmento do espaço no qual as pessoas têm relação de pertencimento e de reconhecimento, a qual seria formada por dois elementos básicos: um de ordem física (território demarcado) e outro de ordem social (simbólico, rede de relações). Nessa concepção, o "pedaço" pode ser a própria quadra da escola de samba ou o local onde suas atividades se dão.

As escolas de samba originadas de torcidas organizadas, por exemplo, praticamente não mantêm vínculos de pertencimento com $\mathrm{o}$ bairro onde se localizam. É o caso da Escola de Samba Gaviões da Fiel, cujo elo fundamental é o Sport Club Corinthians Paulista, embora possua grande estrutura em sua sede, no bairro do Bom Retiro, como a quadra de ensaios, o barracão e um centro social e esportivo. E como torcida organizada, possui subsedes em diferentes cidades, com um total aproximado de setenta mil associados pagantes. Essas e outras características a diferenciam absolutamente das escolas que não têm sua origem vinculada a uma torcida de futebol, fatores que levaram a uma tentativa, sem sucesso, no interior da Liga, de criar um grupo separado de escolas esportivas.

Já a Escola de Samba Unidos de Vila Maria, por exemplo, conta com uma comunidade de bairro muito presente, evidenciando relações de parentesco e vizinhança. Tem forte atuação social e muitas parcerias com empresários e comerciantes, não apenas do distrito de Vila Maria, mas, também, de distritos vizinhos como Vila Medeiros e Vila Guilherme, além de uma relação próxima com a Subprefeitura, o que, inclusive, é visto como algo positivo entre seus diretores e componentes.

É comum as escolas de samba, mesmo aquelas que possuem quadra, realizarem ensaios nas ruas dos bairros com a finalidade de vivenciar uma situação com características mais próximas daquelas que encontrarão na passarela oficial, o que o 
formato da quadra não permite. Isso, por sua vez, contribui para a manutenção de um vínculo mais próximo com os moradores e com o seu lugar, o que ainda é muito importante para o sucesso da escola.

Apesar das rígidas características do desfile na atualidade, algumas escolas também desfilam em seus bairros após cumprirem sua obrigação na passarela oficial, em especial aquelas que ainda mantém forte ligação com o seu lugar de origem. Em muitos casos, isso é algo predeterminado, fazendo parte do calendário da agremiação. O desfile no bairro é um momento de grande descontração e, embora não conte com os carros alegóricos utilizados no Sambódromo, são carregados de beleza e muita animação.

Essas características revelam que, mesmo entre as grandes escolas, ainda se verifica a continuidade da manifestação nas ruas dos bairros, independentemente da existência do Sambódromo e das transmissões pela Rede Globo de Televisão, e ainda que de forma residual, pois, apesar da imposição externa de formas e valores relacionados à realização do desfile carnavalesco, as relações criadas no lugar, possibilitadas pela contiguidade e pelos laços de vizinhança, se fortalecem, criando a necessidade de reproduzir a manifestação no bairro.

Isso evidencia outra territorialidade e a existência de horizontalidades, ou seja, de uma rede de relações criadas no cotidiano e fortemente ligadas ao lugar. E, como afirma Santos (1999, p. 228), "as forças oriundas do local, das horizontalidades, se antepõem às tendências meramente verticalizantes". Mas trata-se da manifestação renovada, não cabendo a comparação simples com o que se verificava na primeira metade do século $X X$, bem como não pode ser analisada fora do contexto de adaptação à cidade em crescimento.

\section{A ação social das escolas de samba - formas e abrangências}

O carnaval das escolas de samba na cidade de São Paulo apresenta-se como um espetáculo da indústria cultural. Mas é, também, uma festa popular, produto de uma comunidade unida em torno de um objetivo: a produção do carnaval em todas as suas minúcias. De modo geral, as escolas de samba desempenham diversas funções para sua comunidade e reconfiguram, de certa forma, o lugar onde se localizam, além de fomentar uma série de relações sociais em suas atividades cotidianas. Ou seja, as inovações que por um lado alteraram a estrutura organizacional e produtiva das escolas, por outro, criaram novas possibilidades no que se refere à atuação e às relações das comunidades em suas agremiações. Como afirma Bosi:

[...] a exploração, o uso abusivo que a cultura de massa faz das manifestações populares, não foi ainda capaz de interromper para todo sempre o dinamismo lento, mas seguro e poderoso da vida arcaico-popular, que se reproduz quase organicamente em microescalas, no interior da comunidade, apoiada pela socialização do parentesco, do vicinato e dos grupos religiosos (BOSI, 1992, p. 329).

Embora o foco das entidades seja a produção dos desfiles carnavalescos, é possível observar a tomada de consciência, por parte alguns dirigentes e componentes, da importância social e cultural dessas agremiações e, como consequência, surge 
uma preocupação em utilizá-las, também, com a finalidade de desenvolver ações no sentido de suprir as necessidades mais imediatas da comunidade. O conjunto dessas ações é o chamado trabalho social desenvolvido nas escolas de samba, o qual pode ocorrer de diversas formas.

As ações em si não são uma novidade do período atual, pois já nas décadas de 1980 as escolas desenvolviam ações assistencialistas, tais como a distribuição de cestas básicas, campanhas com a finalidade de obter recursos ou objetos que seriam revertidos ou doados à comunidade, serviços médicos, entre outras coisas. Essas ações permanecem e vêm adquirindo força, o que por um lado é muito interessante, em especial no que se refere àquelas voltadas à área da saúde, uma vez que existe uma parcela significativa da população que não tem acesso universal a esse serviço; mas, por outro lado, essas ações não têm força alguma no sentido de alterar a situação geradora do problema.

A novidade do período reside no conteúdo das novas ações desenvolvidas no sentido de promover a formação e a geração de renda para a comunidade e, dessa forma, criar possibilidades de superação do problema. A nova estrutura das escolas de samba - quadra, barracão, equipamentos internos, recursos financeiros - embora atenda aos interesses da indústria cultural, uma vez que se estabelece para a produção do desfile transmitido pela televisão, cria condições para que a comunidade a utilize como meio de inserção e de superação da escassez a que é submetida. Multiplicam-se os trabalhos desenvolvidos com a finalidade de atender suas necessidades, preenchendo, de alguma forma, as lacunas deixadas pelo poder público que, mais atento aos interesses hegemônicos e do mercado, desampara a grande massa da população, pois o desenvolvimento da cidade de São Paulo não levou à superação da desigualdade e da pobreza; pelo contrário, as intensificou.

Nesse contexto desenvolvem-se diferentes projetos de fomento à cultura e ao lazer, formação e capacitação profissional, geração de trabalho e renda, atendimento à saúde, assessoria jurídica, entre outros. Vale lembrar que algumas dessas atividades têm relação direta com a produção do carnaval como, por exemplo, os cursos profissionalizantes que visam atender a este mercado. Mas essas ações não se realizam em todas as escolas de samba e, devido ao maior acesso aos recursos materiais, são as maiores escolas que realizam as ações mais abrangentes. Em alguns casos, devido à carência de equipamentos culturais e de lazer, a própria existência da escola de samba, seja grande ou pequena, se caracteriza como uma ação social, pois oferece aos moradores opções de lazer e entretenimento.

Além de atender às necessidades da comunidade, essas ações são desenvolvidas com a finalidade de melhorar a imagem das agremiações ante sua comunidade, a população do bairro e a sociedade paulistana de modo geral. Pois, apesar das inovações e do desenvolvimento das agremiações carnavalescas, muitos vizinhos ainda as veem, em especial as menores, como entidades pouco familiares frequentadas por pessoas de índole duvidosa. Além disso, as ações sociais são vistas como diferenciais no momento da obtenção de patrocínios, pois os possíveis patrocinadores, seja através do tema do enredo ou da Lei Rouanet, optam 
por associar sua marca a uma instituição notadamente idônea que ofereça uma contrapartida à sociedade.

A partir da análise das ações realizadas nas escolas de samba é possível classificá-las em dois grupos: ações externas, que se originam a partir de instituições que buscam a parceria das escolas de samba para efetivar seus projetos de atendimento social, mesmo que o curso oferecido seja definido pela agremiação; e ações internas, que se originam nas escolas de samba que, por sua vez, também buscam parcerias externas, em especial para a obtenção de recursos financeiros.

Para compreender as ações das escolas de samba nos bairros, foram analisadas duas entidades de diferentes tamanhos e localizadas em diferentes pontos da cidade, são elas: Unidos de Vila Maria e Príncipe Negro da Cidade Tiradentes. Trata-se de uma breve aproximação que certamente não esclarece a totalidade das relações, mesmo por que, como lembra Arroyo (1996, p. 79), a totalidade não é "homogênea ou uniforme; ao contrário, ela se compõe de especificidades, de complexidades, de conflitos tanto das estruturas quanto das formas. A totalidade sem contradições é vazia e inerte; sua concreticidade está determinada pelas contradições".

\section{G.R.C.S.E.S. Unidos de Vila Maria}

Fundada em 1954, a Escola de Samba Unidos de Vila Maria esteve presente durante todo o tempo no carnaval paulistano. Mas devido a uma série de problemas relacionados à má administração e por uma incapacidade de adaptação às imposições decorrentes da oficialização em 1967, passou longo período fora do grupo de elite, retornando apenas em 2002, onde permanece até então, embora ainda não tenha sido campeã. Em 2003 a agremiação inaugurou sua quadra - a maior de São Paulo - localizada em um terreno público ao lado do Clube Municipal Cecília Meireles, concedido pela prefeitura por cinquenta anos, onde se localiza também o seu barracão. Anteriormente à sua construção, os ensaios ocorriam em diferentes pontos do bairro.

A força dessa escola de samba reside na presença e atuação de sua comunidade que, embora não seja, exclusivamente, do bairro, está fortemente concentrada no distrito de Vila Maria e nos distritos vizinhos. A existência da escola de samba no distrito de Vila Maria contribui para o desenvolvimento do lugar, uma vez que gera empregos diretos e indiretos e movimenta o comércio local, além de funcionar como um espaço de lazer e cultura para a comunidade, estimulando relações de sociabilidade, pois na quadra se realizam os ensaios para o carnaval, além de diversas atividades, como shows, festas, eventos, cursos de formação e capacitação para pessoas de diversas idades, entre outras atividades.

A análise das fichas cadastrais dos associados revelou que, embora a imensa maioria dos associados à Escola de Samba Unidos de Vila Maria seja do próprio bairro, ela apresenta grande abrangência, extrapolando os limites do distrito de Vila Maria e, mesmo, do município de São Paulo (Mapa 1). O que comprova a ideia de que o vínculo e a identidade também se dão, grandemente, a partir da própria agremiação. 
Mapa 1 - Associados à escola de samba Unidos de Vila Maria por distrito de origem

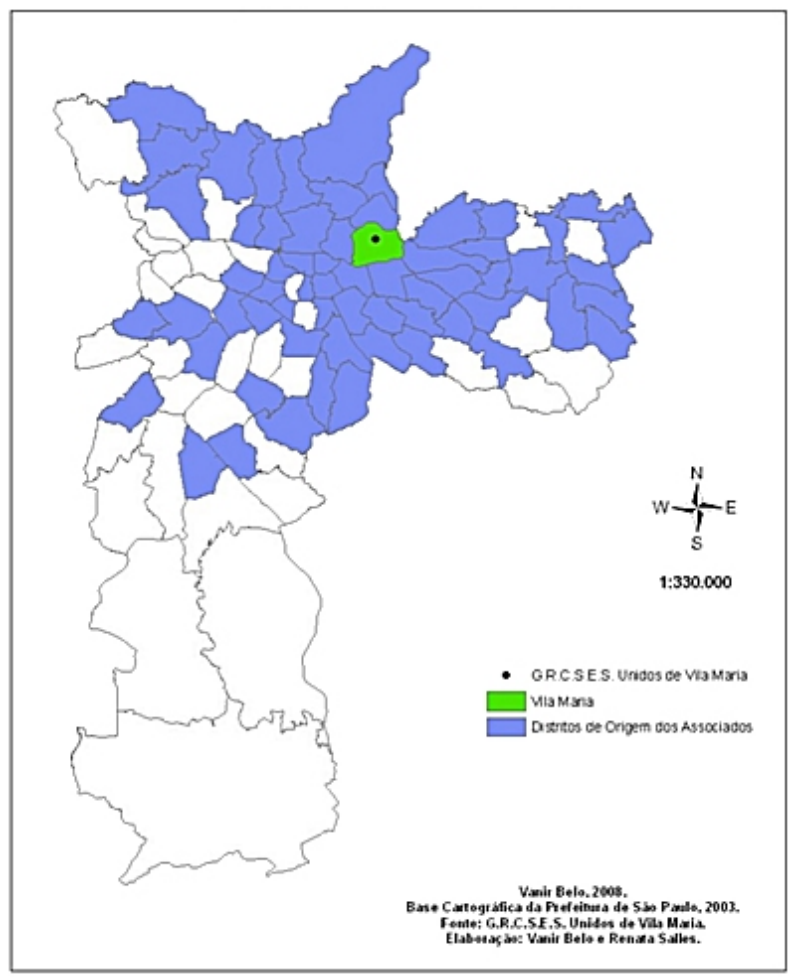

Essa abrangência, também observada em outras escolas, leva à ampliação da rede de relações e, consequentemente, cria oportunidades de ação, fortalecendo a agremiação não apenas no que se refere ao carnaval, mas, principalmente, como entidade socialmente organizada. No bairro de Vila Maria e região a escola de samba não é a única instituição capaz de fomentar e fortalecer tais relações, mas uma escola de samba da forma como se organiza e se estrutura na atualidade, apesar de seu caráter cada vez mais empresarial, tem um poder de atração muito forte por diversos aspectos. Em especial nos lugares onde são poucas as opções de lazer barato ou gratuito e onde há concentração de população com baixo poder aquisitivo ou desempregada; pois ao mesmo tempo em que oferece lazer, cultura e entretenimento, oferece, também, cursos de formação e capacitação, além de oportunidades de trabalho (Quadro 1).

\section{Quadro 1}

\begin{tabular}{||c|c|}
\hline \multicolumn{2}{|c|}{$\begin{array}{c}\text { QUADRO 1. G.R.C.S.E.S. UNIDOS DE VILA MARIA - } \\
\text { ATIVIDADES DIRECIONADAS A COMUNIDADE }\end{array}$} \\
\hline Cursos Gratuitos & Vagas Oferecidas \\
\hline Corte e Costura & 28 \\
\hline Eletricista & 28 \\
\hline Depilação & 25 \\
\hline Manicura & 25 \\
\hline Cabeleireiro & 50 \\
\hline Maquiagem & 20 \\
\hline Audio-Visual & 20 \\
\hline Violão & 45 \\
\hline Cavaquinho & 36 \\
\hline Escolinha de Bateria & 120 \\
\hline Informática & 40 \\
\hline Turismo & 20 \\
\hline Departamento De Pessoal & 30 \\
\hline Futebol da Campo & 250 \\
\hline Capoeira & 20 \\
\hline Ginástica Melhor Idade & 50 \\
\hline Outras Ações & 150 \\
\hline Atendimento odontológico & 111 \\
\hline Atendimento clinica geral & 352 \\
\hline Atendimento fisioterápico & 100 \\
\hline Atendimento psicológico & Pessoas Atendidas \\
\hline Orientação Juridica & 2050 \\
\hline
\end{tabular}

Fonte: Departamento Cultural - G.R.C.S.E.S. Unidos de Vila Maria, 2007. Elaboração da autora.

Como é possível verificar no quadro apresentado, a Escola de Samba Unidos de Vila Maria realiza importante trabalho sociocultural. São projetos desenvolvidos através de parcerias com as iniciativas pública e privada, cujo objetivo é, entre outros, "melhorar a qualidade de vida da comunidade local, afastando crianças e adolescentes do envolvimento com as drogas, marginalidade, proporcionando-lhes Cultura, Educação, Saúde e Lazer" (Departamento Social, www.unidosdevilamaria.com.br, acesso em: jan. 2008).

Os cursos e serviços oferecidos pela escola de samba Unidos de Vila Maria são gratuitos, realizados em parceria com diversas instituições e organizações não governamentais, tais como Prefeitura, Subprefeitura da Vila Maria e Vila Guilherme, escolas de educação básica, Secretaria 
Estadual da Cultura, Prefeitura, SEBRAE, Ministério da Cultura, entre outras. Há, por exemplo, o Projeto Cultura Viva, existente desde 2004, que engloba os cursos relacionados à arte e à cultura, o qual é ligado ao projeto Teia Cultura Viva do Ministério da Cultura.

Os diversos trabalhos culturais e sociais realizados pela Escola de Samba Unidos de Vila Maria e a sua abrangência, atraindo pessoas das mais diversas localidades, revelam a força e as possibilidades de ação de uma agremiação carnavalesca quando faz uso das técnicas e políticas disponíveis em benefício do seu carnaval e de sua comunidade, o que se traduz em uma ação efetiva no lugar onde se localiza.

\section{G.R.C.E.S. Príncipe Negro da Cidade Tiradentes}

A Escola de Samba Príncipe Negro da Cidade Tiradentes foi fundada pela primeira vez em 1964, no bairro de Vila Prudente, com o nome Príncipe Negro de Vila Prudente. Tratava-se de uma escola de base familiar e originada de um time de futebol. Devido a uma série de problemas enfrentados, encerrou suas atividades e as reiniciou em 1983, no mesmo bairro. No entanto, a escola sofria dificuldades devido ao aumento do preço da terra e a consequente mudança de boa parte de seus integrantes para outros bairros da cidade. Vila Prudente tornou-se um bairro de classe média onde a escola não tinha espaço e não era aceita.

Com a mudança da família que se caracterizava como o núcleo duro da agremiação para a Cohab Cidade Tiradentes, a escola começou a integrar novos componentes residentes neste bairro e, em pouco tempo, passou a ser praticamente toda formada por moradores da Cohab. No entanto, seu endereço permanecia na Vila Prudente. Após três anos nessa situação, os novos componentes passaram a cobrar a mudança do endereço da escola para a Cidade Tiradentes, o que ocorreu em 1993, quando a escola migrou definitivamente para o novo bairro, alterando seu nome para Príncipe Negro da Cidade Tiradentes. Atualmente, esse bairro conta também com a Escola de Samba Estrela Cadente, fundada em 2001 por antigos componentes do Príncipe Negro.

A Escola de Samba Príncipe Negro da Cidade Tiradentes possui apenas uma sede, o bar da família da presidenta, localizado na garagem do prédio onde mora. Essa agremiação, a exemplo de diversas outras, não possui quadra para ensaios e tampouco barracão para construir seus carros alegóricos. Os ensaios, que chegam a contar com cerca de quinhentas a setecentas pessoas entre componentes e espectadores, ocorrem na pequena praça que é, também, um ponto de táxi em frente ao bar, na quadra poli esportiva localizada ao lado do prédio e, nos últimos ensaios antes do carnaval, pelas ruas do bairro.

Essa agremiação depende fortemente da comunidade e dos moradores de seu bairro para se realizar. Por isso, seus organizadores procuram desenvolver projetos sociais e culturais em parceria com a Prefeitura e outras entidades para atender a essas pessoas. Mas o fato de não possuir uma quadra dificulta a realização de projetos. Diante disso, a escola encaminha seus componentes para participar de atividades 
desenvolvidas por outras entidades, mas também desenvolve algumas atividades utilizando os espaços físicos do clube, de escolas públicas, de associações comunitárias e de outras entidades presentes no bairro.

Dentre as ações desenvolvidas, os componentes (entrevistados em maio de 2007) citam: o time de futebol com várias categorias; o projeto Recreio nas Férias, em parceria com a Prefeitura; um curso de adereços iniciado em 2008, em parceria com - Governo Federal, e diversos cursos relacionados a atividades artísticas e culturais. O objetivo desses projetos é proporcionar oportunidades para a comunidade e, também, melhorar a imagem da agremiação perante os moradores do bairro.

Os componentes dessa agremiação também citaram como atividades significativas, a festa junina, a comemoração ao dia de São Cosme e São Damião com distribuição de doces para as crianças, confraternizações diversas e as romarias para a cidade de Tietê, por ocasião da Festa de São Benedito. Todas essas ações são realizadas com a contribuição e o trabalho voluntário de seus componentes, dentre os quais muitos líderes e membros de outras associações atuantes no bairro.

Devido à sua popularidade, a escola de samba é também convidada para participar de diversos eventos que ocorrem no local e em bairros vizinhos, o que faz sem cobrar nada. Dentre as atividades foram citadas: inauguração de supermercado, de sacolão, de posto de saúde, desfiles cívicos, festas realizadas nas escolas públicas, no Batalhão dos Bombeiros, casamentos comunitários etc. Além de emprestar instrumentos, fantasias e outros objetos para realização de eventos como peças de teatro, festas e aniversários, muitos dos quais realizados na sede da escola, buscando a integração com diferentes setores do bairro.

Essas ações e interações revelam a força e as diversas possibilidades dessas agremiações nos bairros onde se localizam, e atraem a simpatia e a colaboração de diversas entidades e pessoas, mesmo aquelas que, por diferentes motivos, não gostam de - ou não acompanham - carnaval. O taxista do ponto da praça, que já se tornou amigo, fia corridas quando há necessidade; os evangélicos residentes no prédio onde se localiza a sede oferecem suas garagens para a escola guardar seus pertences e afirmam que a colocam em suas orações para que tudo corra bem e para que realizem um bom desfile; o dono da padaria, embora não contribua financeiramente, torce e acompanha o desempenho da escola; nos dias de ensaio, os jovens que jogam basquete deixam metade da quadra livre para que os casais de mestre-sala e portabandeira também possam utilizá-la para ensaiar.

Os componentes se orgulham ao afirmar que durante os ensaios não é comum a ocorrência de problemas e tampouco o uso de drogas na redondeza, pois todos sabem que se trata de um "evento familiar" e ficam atentos para que nada ocorra; mas, de todo modo, os organizadores solicitam policiamento preventivo. Há distribuição de preservativos por parte de uma associação do bairro e, eventualmente, ocorrem palestras sobre saúde, nos dias de ensaio. E embora não haja reclamações de vizinhos em relação ao barulho, as atividades sempre terminam antes das duas horas da madrugada. 
Os componentes da Escola de Samba Príncipe Negro valorizam o fato de realizar atividades ao longo de todo o ano, de manter as tradições de uma escola de samba e de ser uma agremiação familiar e que aproxima famílias, uma vez que a convivência promove a criação de laços de compadrio e de parentesco.

A presidenta, que a princípio não aprova o processo de profissionalização da forma como ele se dá, reconhece que a escola de samba não é economicamente importante para o bairro, mas afirma que, culturalmente, tem uma importância fundamental, pois formou diversos sambistas, enraizou o samba na Cidade Tiradentes e levou o nome do bairro para o carnaval paulistano.

Por se tratar de uma escola de samba, atualmente, do Grupo II, a Príncipe Negro não conta com verba oficial significativa para realizar seu carnaval e não obtém patrocínio junto aos comerciantes locais. Mas dispõe de uma comunidade unida e disposta a trabalhar voluntariamente. De modo geral contrata-se um ou dois profissionais especializados em determinadas tarefas, como a construção de esculturas, mas os demais trabalhos são realizados em conjunto pela comunidade em suas próprias casas, pois a escola não possui um barracão; os carros alegóricos normalmente são construídos em um terreno baldio. Alguns componentes como destaques de carro e de chão, mestre-sala e porta-bandeira, corte e diretores, além de contribuir para a confecção de suas fantasias, caso queiram deixá-las mais incrementadas e mais bonitas devem também arcar com os custos adicionais.
Para baratear os custos, a escola recicla o material utilizado no ano anterior e adquire os novos materiais diretamente dos fabricantes; inclusive de cidades do interior. Para aumentar a receita, vende agasalhos e camisetas da agremiação e realiza rodas de samba com venda de feijoada cujos ingredientes são fornecidos pelos próprios componentes.

Apesar dos diversos problemas enfrentados na produção do carnaval, os componentes afirmam que estão muito bem, se comparando ao que já passaram; como, por exemplo, o fato de terem usado como carro abre-alas, no início da década de 1990, um carrinho de cachorro quente e uma porta de apartamento enfeitados e com o nome da escola escrito. Hoje, podem ajudar escolas menores doando estruturas de carros antigos, prática muito comum no passado - a própria agremiação já recebeu esse tipo de ajuda - porém, pouco realizada na atualidade pelas grandes escolas que costumam vender o material que não será utilizado.

Por dois anos, 1997 e 1998, o desfile oficial ocorreu na Cidade Tiradentes, o que, para a agremiação, foi ótimo devido a uma grande economia com o transporte dos carros alegóricos. Pois, embora recebam da UESP uma ajuda de custo para essa finalidade, o valor no geral não é suficiente para cobrir toda a despesa. Por diversos anos desfilou em passarelas montadas na Zona Leste, o que também facilitava e possibilitava a ida dos moradores do bairro que torcem pela escola. Mas, nos últimos anos, desfilou na passarela montada no autódromo de Interlagos e enfrentou muita dificuldade devido à distância, inclusive uma leve diminuição no número de componentes. Isso revela que as longas distâncias existentes 
entre a sede da escola e o local de desfile são um fator de desestímulo. Os componentes criticam não apenas a distância, mas, também, a falta de estrutura para a realização dos desfiles no autódromo, por tratar-se de um lugar ermo e com uma pista inadequada.

As características da Escola de Samba Príncipe Negro da Cidade Tiradentes revelam a importância cultural e social de uma agremiação carnavalesca em um bairro periférico da cidade de São Paulo que conta com uma pequena oferta de equipamentos culturais e de lazer. Nesse caso, a própria existência da escola de samba, se traduz em uma ação social, pois trata-se de uma entidade que tem grande capacidade de agregar pessoas de diferentes idades, incluindo aquelas que não têm relação com o samba e com o universo do carnaval e possibilitar momentos de sociabilidade.

\section{Considerações finais}

Durante todo o processo de desenvolvimento, normatização e adaptação aos conteúdos urbanos, as escolas de samba se empenharam em potencializar a produção dos desfiles carnavalescos através da especialização da mão de obra, do estreitamento e da ampliação das relações com diversos agentes dos diferentes circuitos da economia urbana que, por sua vez, se aproximam das escolas de samba com a finalidade de incrementar seus negócios, de diferentes portes.

Nesse contexto há uma multiplicação das divisões social e territorial do trabalho geradas na produção carnavalesca que, para se realizar, passa a integrar uma série de agentes, criando e ampliando circuitos de produção e cooperação que extrapolam gradativamente os limites do bairro, da cidade e do país, ampliando, assim, a abrangência dos fluxos e as escalas dos eventos.

Essa situação, que entre os agentes envolvidos é chamada de "profissionalização do carnaval" alterou a estrutura organizacional e produtiva do carnaval paulistano com a finalidade de desenvolvê-lo e ampliar os negócios afins. Cria-se um mercado profissional que altera as relações de trabalho e a identificação com a escola de samba. Todavia, essas inovações na forma de produzir os desfiles não se difundiram de forma homogênea entre as agremiações carnavalescas, havendo uma sobreposição de divisões do trabalho geradas em diferentes momentos e coexistindo na atualidade. Sobreposição possível de ser observada inclusive no interior de uma mesma escola de samba.

O acesso aos novos conteúdos urbanos e a ampliação das formas de uso da cidade, associada a uma tomada de consciência por parte de alguns dirigentes e membros das escolas de samba, criaram possibilidades de ações sociais voltadas ao atendimento das necessidades mais imediatas das comunidades, através das entidades carnavalescas. Ações que, por outro lado, contribuem para atração de investimentos que são revertidos para a produção do desfile. Os recursos utilizados nessas ações podem ser obtidos através das mais diversas formas de parcerias e doações.

Nesse contexto as escolas maiores que dispõem de recursos humanos e materiais, tais como quadra de ensaio e 
pessoas dispostas a trabalhar, remuneradas ou não, possuem maiores possibilidades de ação cada vez mais abrangentes. Todavia, em alguns casos, a própria existência das escolas de samba como entidades promotoras de sociabilidade, lazer e entretenimento, em lugares desprovidos de equipamentos básicos, se caracteriza como uma ação sociocultural importante. As diferentes situações das escolas analisadas nesta pesquisa mostraram as diversas possibilidades de abrangência dessas ações.

Os novos conteúdos do carnaval paulistano não se fazem presentes em todas as agremiações, ao menos não com a mesma intensidade, sendo possível verificar na atualidade, em especial nas chamadas "pequenas escolas", diversas características comuns aos períodos anteriores à oficialização, tais como uma rede de relações e de solidariedades baseadas em laços familiares e de vizinhança, fortemente atrelada ao lugar onde elas se localizam. Ao passo que outras entidades, em especial as chamadas "grandes escolas", embora ainda possam apresentar núcleos familiares centrais ou fortes relações com o lugar onde se estabelecem, estruturam-se de forma muito próxima a uma organização empresarial e têm uma grande abrangência, atraindo pessoas de diversos lugares e se estabelecendo fisicamente em diferentes pontos da cidade, como, por exemplo, instalando barracões nas proximidades do Sambódromo com a finalidade de facilitar o acesso ao local do desfile e baratear os custos.

Nesse contexto, as ações sociais desenvolvidas pela escola de samba se constituem como elementos importantes e contribuem para a criação e manutenção dos vínculos entre a população do entorno e a entidade. Essa aproximação leva à compreensão de que a escola de samba como entidade organizada pode ter múltiplas funções. As ações revelam a criação de solidariedades e a ampliação de horizontalidades, tanto no bairro como a cidade, onde é possível observar uma rede de relações horizontais formada pelo conjunto das agremiações que agem nesse sentido, as quais se utilizam dos novos conteúdos, materiais e imateriais, para promover essas ações que se caracterizam como contraracionalidades ou racionalidades paralelas, (SANTOS, 1999). ${ }^{3}$ Esse processo corrobora a ideia de que sua compreensão, bem como de outras manifestações culturais, é de fundamental importância para o entendimento da cidade.

\footnotetext{
${ }^{3}$ Segundo Milton Santos, "o fato de que a produção limitada de racionalidade é associada a uma produção ampla de escassez conduz os atores que estão fora do círculo da racionalidade hegemônica à descoberta de sua exclusão e à busca de formas alternativas de racionalidade, indispensáveis a sua sobrevivência" (1999, p. 247).
} 


\section{Referências bibliográficas}

ARROYO, M. Território, transição e futuro. Experimental, São Paulo: LaboplanFFLCH-USP, n. 1, p. 77-85, jul. 1996.

BOSI, A. Dialética da colonização. 3. ed. São Paulo: Companhia das Letras, 1992.

MAGNANI, J. G. C. De perto e de dentro: notas para uma antropologia urbana. Revista Brasileira de Ciências Sociais, v. 17, n. 49, p. 11-29, jun. 2002.

SANTOS, M. Lazer popular e geração de empregos. In: Lazer numa sociedade globalizada: Leisure in a globalized society. São Paulo: Sesc/WLRA, 2000. p. 31-37.

A natureza do espaço: espaço e tempo, razão e emoção. 3. ed. São Paulo: Hucitec, 1999.

. O espaço dividido: os dois circuitos da economia urbana nos países subdesenvolvidos. Rio de Janeiro: Francisco Alves, 1979.

SEABRA, O. C. L. Urbanização: bairro e vida de bairro. Travessia, São Paulo, $\mathrm{n}$. 38, p. 11-17, set. 2000. 